\title{
Virtual Reality Active Games as a Potential Tool to Enhance Movement Skills and Promote Participation in Physical Activities for Children with DCD: Pilot Study
}

\author{
Amy Werden, Eryk P Przysucha* and Carlos Zerpa \\ School of Kinesiolgy, Lakehead University, Canada
}

Submission: July 13, 2017; Published: July 31, 2017

*Corresponding author: Eryk Przysucha, School of Kinesiolgy, Lakehead University, 955 Oliver Road Thunder Bay, Ontario, Canada P7B-5E1, Canada, Tel: 807-343-8189; Fax: 807-343-8944; Email: eprzysuc@lakeheadu.ca

\begin{abstract}
Children with developmental coordination problems exhibit difficulties performing even seemingly simple motor tasks, discouraging them from engaging in age appropriate physical activities. It appears that playing active video games may have a positive impact on certain aspects of their motor performance and the willingness to be physically active. The purpose of the present pilot study was to examine if these positive effects can be evident in two children with Developmental Coordination Disorder (DCD) playing selected Xbox Kinect sports games. One eleven year old boy and a nine year old girl, diagnosed with DCD, were assessed using Movement Assessment Battery for Children (MABC2) and selected components of Bruininks Oseretsky Test (BOT2) at pre, mid, and post sessions, and two weeks after the program. Children engaged in Wake Racing, Climbing, Soccer, and Tennis games, in two 40-minute sessions per week, for 6 weeks. The parents and the children were also involved in an interview at the end of the study. The results from the formal assessment tools showed that both children improved in balance and ball skills subsections of the MABC2. However, the data from BOT2 failed to show the expected effects on running speed and agility, and in the strength domain. The interviews with children revealed that playing games was enjoyable and could potentially affect their willingness to take part in active play. This was confirmed by parents, who also were interested in implementing this protocol within the home setting. However, the degree to which the skills acquired/refined while playing active video games transfer to real-life tasks requires further investigation.
\end{abstract}

Keywords: Developmental coordination disorder; Innovative clinical treatment; Movement skills; Motor abilities

\section{Introduction}

Video games undeniably represent one of the most popular sources of entertainment for children and adults of all ages. They are available on a large spectrum of systems, from consoles accompanied to televisions, hand held devices, and mobile phones. In fact, $32 \%$ of $2-7$ year olds and $65 \%$ of $8-18$ year olds in America have television sets accompanied with some sort of video games [1]. This is troublesome for many health professionals who rightly perceive the engagement in such games as yet another barrier to being active, particularly for children [2]. Nevertheless, despite these concerns research has shown that if the games involve active movements they may actually have positive effects on the acquisition or relearning of certain motor skills [3]. This is not to say that video-games will or should replace the time spent engaging in active and meaningful physical activities. However, these games offer an opportunity to learn the basic movement skills in an environment that is nonthreatening, fun, supportive and engaging. Thus, such games may represent a temporary but valuable alternative for individuals who are often unwilling to engage in active play/activities due to their low skill or fitness levels and coinciding low perceptions of competency and feelings of social unaptness.

From the clinical perspective, implementation of active virtual games (Sony's PlayStation, Nintendo Wii, and Microsoft Xbox Kinect) constitutes a useful approach as many individual, task and environmental constraints can be altered to assure success. Also, the fact that the performer has the opportunity to practice a number of distinctive skills, or perform a singular skill under different task and/or environmental-virtual conditions, is 
conceptually relevant. The former condition is synonymous with the premise of contextual interference [4], whereas the former approach is in line with schema theory and variability of practice hypothesis [5], two of the most robust concepts in contemporary motor learning literature. It has been also suggested that the implementation of virtual games may stimulate implicit learning and positively affect the variety of perceptual motor domains which otherwise would be difficult to enhance if the child was unwilling to take part in any physical activity [6]. These positive effects have been evident in studies involving children with Down syndrome [7], attention deficit hyperactivity disorder (ADHD) [8] and those without any known medical conditions but who are overweight [9]. Also, there has been some initial research carried out with children diagnosed with Developmental Coordination Disorder (DCD), however the results remain equivocal.

Children with DCD account for 6 to $10 \%$ of school aged children and exhibit movement problems that are due to factors other than known medical conditions or intellectual disability [9]. Also, they exhibit motor learning difficulties [10] which prevent them from acquiring or mastering different motor abilities (e.g. agility, strength, hand-eye coordination), as well as fundamental (e.g. throwing, catching, balancing) and specialized movement skills (e.g. activities of daily living). Due to these movement constraints they exhibit repeated failures when performing even seemingly simple tasks. As a result, they often are ridiculed and bullied, becoming reluctant to participate in physical activities in socially relevant contexts (school, playground; sport settings). This further deteriorates their movement repertoire and jeopardizes their chances of meaningful interaction with their peers [11].

In regards to children with DCD and virtual active games the existing research is valuable, but still relatively limited. Gonsalves [12] reported that when engaged in the active video games children with DCD carried out the tasks differently when compared to their typically developing peers. This is a positive

\section{Instrumentation}

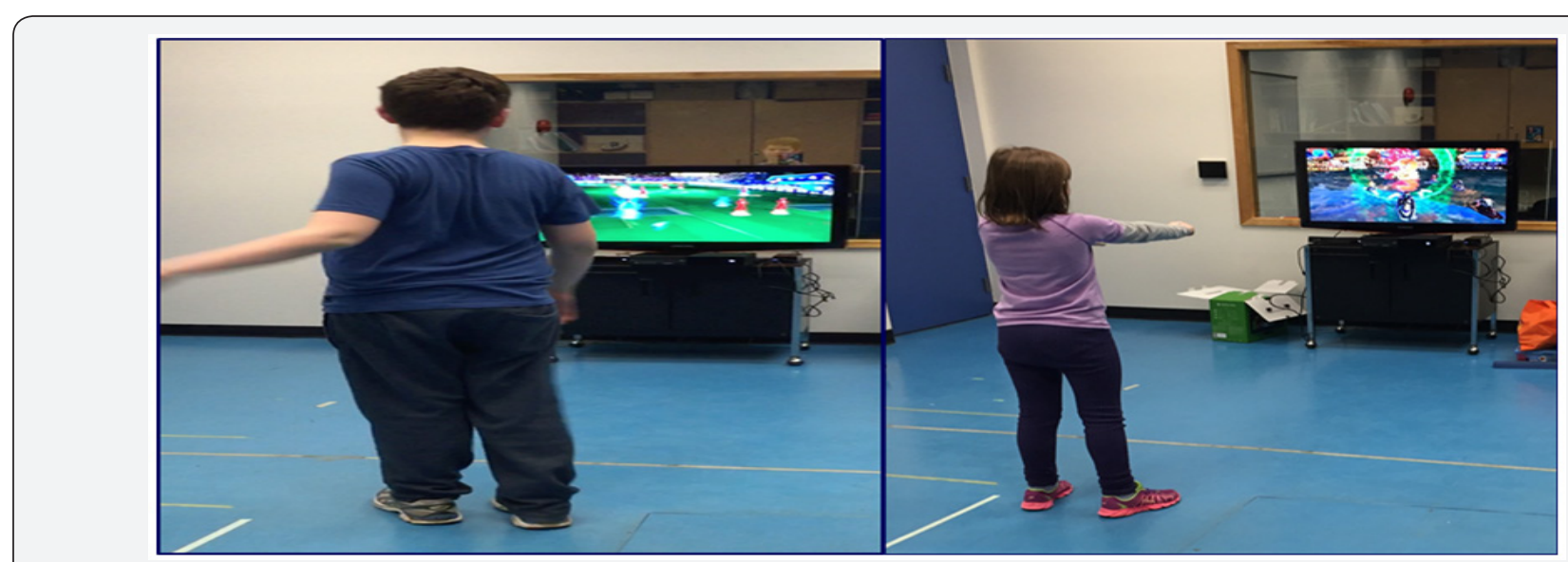

Figure 1: Two factors making advice lists.

finding as it indicates that the activity affords the participant to explore different and possible adaptive movement patterns to accomplish the task at hand. In terms of the other investigations, some failed to show the expected positive effects [13] whereas others revealed that virtual games may in fact constitute an effective clinical tool [14-16]. Among the different aspects of motor functioning there is a robust trend showing that playing active video games has a positive effect on balance control. Also, the anecdotal reports from parents indicated that participation in these games positively transferred to children's ability to play ball games and perform agility and strength related playground skills [17]. However, the available research is still limited as the scope of previous studies focused primarilyon Nintendo's Wii games. Thus it is plausible that different types of virtual reality active games may have positive effects on aspects of motor functioning, other than balance control. Also, a more in depth qualitative analysis of parents' and children's perceptions of the effectiveness and applicability of such approach may provide useful information to researchers and clinicians. As a result, the first purpose of this study was to examine if playing active virtual motion Xbox Kinect games had positive effect on balance control, ball skills, agility and strength in two children with DCD. The secondary objective was to infer whether participation in such games was enjoyable and motivating, based on the perceptions of the children, and if this approach was effective and worth implementing at home, as inferred from parents.

\section{Materials and Methods}

\section{Participants}

One male (11 years of age) and one female (9years of age), diagnosed with DCDby a qualified health professional, were recruited via purposive sampling. They did not exhibit vision problems (e.g. required prescription lenses), and had no previous experience with active virtual games. Also, in order to take part, the parents were asked to refrain their children from any other clinical programs for the duration of the study. 
Kinect system for Microsoft's Xbox 360(Microsoft Inc, Redmond, Washington, USA) was implemented. The user stood facing the TV-screen where the virtual gaming environment was displayed. In this video-capture technology the user does not need any other game controller than naturalistic body movements. A video camera plugged into the gaming console placed a real-time 3D image of the user inside the simulated environment where he/she can move around and interact with virtual objects (Figure 1). Four games were utilized in this study. The game of Tennis involved intercepting and striking the ball thus training one's hand/eye coordination and perceptualmotor integration. The second game was soccer requiring the participant to manoeuver the body to correctly time a kick when the ball was approaching. It is a full body movement involving inter-segmental coordination between the upper and lower body. In the Wake Racing game the participant was represented on the screen as sitting on a Seadoo. The child was required to balance his/her body to manoeuvre the Seadoo around the track. The last game played was Climbing, where the child had to maintained the arms above the head and simultaneously grab for the next hand hold and pull down with the opposite hand to scale the wall. The child was also required to jump to grab for higher hand holds. This game constrained the participant to implement strength, stamina and agility.

\section{Outcome measures}

The Movement Assessment Battery for Children (MABC-2) [18] was used to examine the proficiency in balance control and interceptive ball skills. Manual dexterity was not examined as conceptually there is no link between the activities undertaken and the child's ability to perform fine motor skills. The balance control section was comprised of three items (one-leg standing; walking on the line; jumping) while aiming and catching included two tasks, one related to the respective domain. Each raw score was transformed into a standard score for each task. Generally, the sum of all eight items can be utilized to derive a total standard score and a percentile score. However for this study, only individual standard scores for each section were used as manual dexterity was not tested.

Selected subsections of Bruininks Oseretsky test of motor proficiency (BOT2) [19] were also implemented. The BOT2 encompasses a large spectrum of fine and gross motor skills, however for the purpose of this study only running speed and agility as well as strength sub-sections were considered. Both the running speed and agility and strength portions of the test consist of five tasks. The raw point score for each task was converted into total point score, which was subsequently converted into a scale score.

\section{Qualitative interview}

A semi-structured interview was conducted with both parents and children. A thematic (deductive) interview approach was implemented, utilizing open-ended questions. When interviewing the parents, three main areas of interest were identified. First, the potential changes in the exercise habits of the children were explored. Also, the impact that the intervention had on the child's motivation to participate in physical activity in general, and overall enjoyment of active gaming was inferred. Lastly, the parents were asked about their perception of the usefulness of this approach and the potential to its implementation within the home setting. The interviews lasted approximately 45 minutes.

\section{Procedure}

Table 1: The design of the study depicting the different testing sessions and respective dependent variables.

\begin{tabular}{|c|c|c|c|c|c|c|c|}
\hline Participant & Phase 1 & $\begin{array}{c}\text { Phase } 2 \\
3 \text { Weeks } \\
\text { Intervention }\end{array}$ & Phase 3 & $\begin{array}{c}\text { Phase } 4 \\
3 \text { Weeks } \\
\text { Intervention }\end{array}$ & Phase 5 & 2 Weeks & Phase 6 \\
\hline Male & MABC, BOT & $\begin{array}{c}\text { Xbox } \\
\text { Intervention }\end{array}$ & MABC, BOT & $\begin{array}{c}\text { Xbox } \\
\text { Intervention }\end{array}$ & MABC, BOT & No Intervention & $\begin{array}{c}\text { MABC, BOT, } \\
\text { Qualitative } \\
\text { Interview }\end{array}$ \\
\hline Female & MABC, BOT & $\begin{array}{c}\text { Xbox } \\
\text { Intervention }\end{array}$ & MABC, BOT & $\begin{array}{c}\text { Xbox } \\
\text { Intervention }\end{array}$ & MABC, BOT & No Intervention & $\begin{array}{c}\text { MABC, BOT, } \\
\text { Qualitative } \\
\text { Interview }\end{array}$ \\
\hline
\end{tabular}

The study consisted of six phases (Table 1). In Phase 1, MABC and BOT2 were implemented, as baseline measures. In Phase 2, each participant attended 60-minute sessions twice a week for a period of six weeks, involving virtual games on the Xbox Kinect utilizing the Kinect Sports Rivals game. The primary researcher oversaw all the sessions. The Xbox Kinect system was the training tool. Twenty minutes were allotted for tennis, soccer, wake racing, and climbing games. The same measures that were taken during Phase 1 were administered once again at the three-week mark representing a mid-assessment session (Phase 3). Phase 4 involved additional 3 weeks of intervention, and post-test (Phase 5) was implemented at the end of this time period once again using MABC and BOT2 tests. The retention test (Phase 6) was implemented to infer whether the changes in performance, as inferred from the formal assessment tests, were permanent. Also, qualitative interview with both the child and parents took place during this phase Table 1. 


\section{Design and data analysis}

A case study approach was utilized, with testing time (preassessment, mid-assessment, post-assessment, and retention test) as the independent variable. The dependent variables were the scores gathered through the implementation of the MABC-2 and BOT-2 tests across the different phases of the study. In both tests higher scores represented better performance. Also, the information gathered through the qualitative interviews was utilized to infer the potential effects of gaming on psychological constructs such as motivation and enjoyment.

\section{Results}

\section{Outcome data}

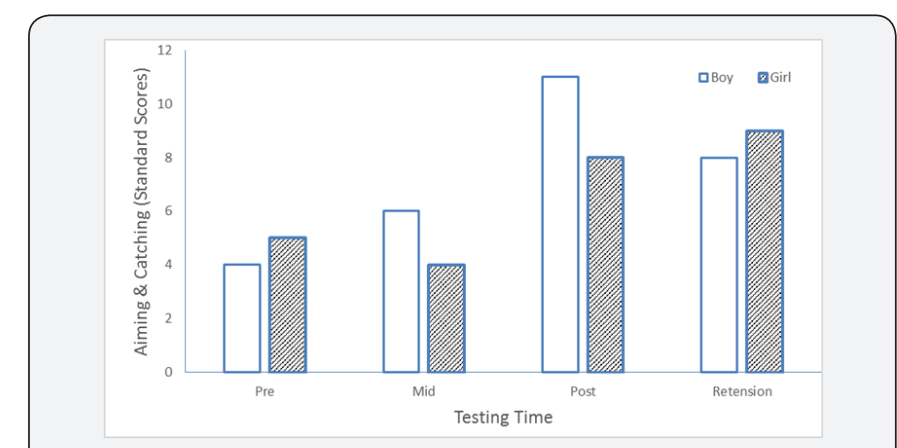

Figure 2: The scores obtained by both participants for Aiming and Catching subsection of MABC2, across the 4 phases of the study.

The standard scores from MABC-2 were used to infer the potential changes in two areas of motor proficiency. In terms of ball skills, as evident from the pre-test data (Figure 2), both children exhibited low skill level. The scores of 4 and 5 coincide with $2^{\text {nd }}$ and $5^{\text {th }}$ percentile respectively, according to the norms provided in the manual [18]. At the post-test, the scores increased considerably, particularly for the male participant whose standard score of 11 corresponds to $63^{\text {rd }}$ percentile. A similar scenario was evident in the performance of the female whose score of 8 placed her at $25^{\text {th }}$ percentile. As evident from the retention test, the enhanced performance was relatively permanent as the scores although lower for the male, were still considerably higher as compared to their initial ball skill status.

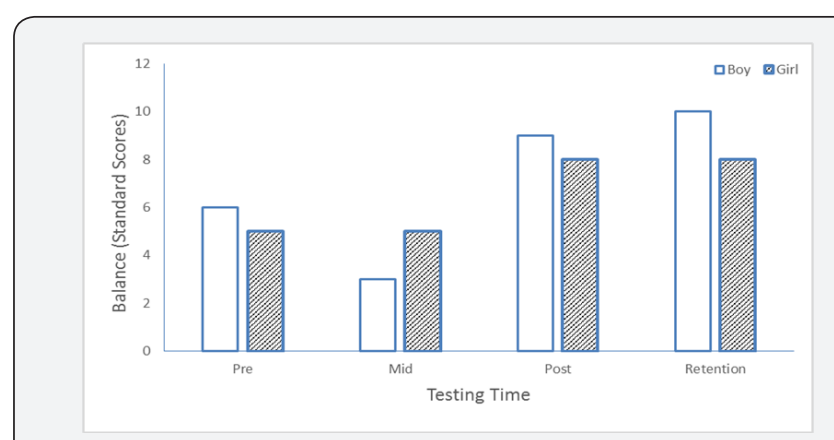

Figure 3: The scores obtained by both participants for Balance subsection of MABC2, across the 4 phases of the study.
The analysis of balance scores (Figure 3) showed a similar scenario as compared to the aiming and catching domain. As evident, both children exhibited scores that would place them at/around the 6thpercentile at the pre-test, indicating low skill level. However, the data collected at the post-test showed a substantial increase in their balance skills, placing them at 63rd and 25th percentile, respectively. The retention test supported that these improvements were permanent.

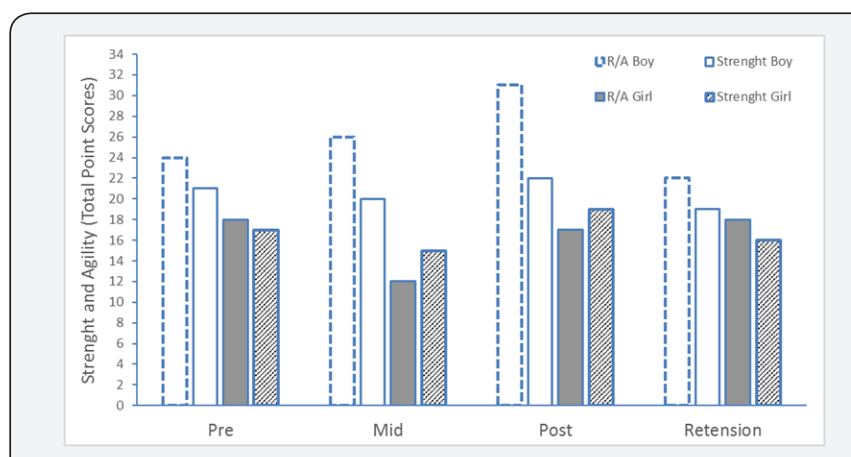

Figure 4: The scores obtained by both participants for selected subsections of BOT2, across the 4 phases of the study.

In order to infer if active video games had an impact on different aspects of motor performance, namely, strength and running speed/agility, two subsections of Bruinkins test were implemented. The scores (Figure 4) showed an equivocal scenario. As evident at the pre-test, the male participant was slightly more capable in the two domains as compared to the female, but both were relatively stable across the two areas. Considering that 52 and 42 are the highest possible scores for running speed/agility and strength, respectively, it is evident that both children exhibited a low skill level in these domains. At the mid- and post sessions, aside from the running and agility score for the male, the other values remained relatively comparable to those achieved at the pre-test. The examination of the retention scores confirmed that the performance was not enhanced as compared to the pre- and post-tests' scores.

\section{Qualitative data}

Table 2: Qualitative data gathered during the interview with the children.

\begin{tabular}{|c|c|c|}
\hline Question & Participant 1 & Participant 2 \\
\hline $\begin{array}{l}\text { Do you think that } \\
\text { you got better at the } \\
\text { games when you } \\
\text { think about how you } \\
\text { did on the first day } \\
\text { and how you did on } \\
\text { the last? }\end{array}$ & "Definitely!" & $\begin{array}{l}\text { "Sometimes I } \\
\text { struggled, but when I } \\
\text { kept on doing it I got } \\
\text { better at it." }\end{array}$ \\
\hline $\begin{array}{l}\text { Would you } \\
\text { recommend these } \\
\text { games to your friends } \\
\text { to play? }\end{array}$ & $\begin{array}{l}\text { "Depends on the } \\
\text { friend, but yes I } \\
\text { would recommend } \\
\text { them, they're fun." }\end{array}$ & $\begin{array}{c}\text { "Yeah because they're } \\
\text { fun." }\end{array}$ \\
\hline $\begin{array}{c}\text { Do you think these } \\
\text { games are similar to } \\
\text { the games you play in } \\
\text { real life? }\end{array}$ & "No, not really." & $\begin{array}{l}\text { "Well not exactly. I } \\
\text { don't go climbing in } \\
\text { real life." }\end{array}$ \\
\hline
\end{tabular}




\begin{tabular}{|c|c|c|}
\hline $\begin{array}{c}\text { What was the most } \\
\text { fun game? And why? }\end{array}$ & $\begin{array}{c}\text { "Tennis! I liked } \\
\text { having to time it. } \\
\text { Most fun." }\end{array}$ & $\begin{array}{c}\text { "Tennis! Because it } \\
\text { was my favourite } \\
\text { sport to do in the } \\
\text { first place and it was } \\
\text { fun." }\end{array}$ \\
\hline $\begin{array}{c}\text { Did you have fun } \\
\text { playing these games } \\
\text { over the past six } \\
\text { weeks? }\end{array}$ & $\begin{array}{c}\text { "Yeah. Not really } \\
\text { climbing or wake } \\
\text { racing." }\end{array}$ & "Yes, yes I did." \\
\hline $\begin{array}{c}\text { Do you think you had } \\
\text { more confidence in } \\
\text { yourself when you } \\
\text { were playing the } \\
\text { games near the end } \\
\text { of the study? }\end{array}$ & "Yeah." & "Yes." \\
\hline $\begin{array}{c}\text { Do you find that you } \\
\text { are having an easier } \\
\text { time in gym class } \\
\text { or at recess after } \\
\text { playing these games? }\end{array}$ & $\begin{array}{c}\text { "Not in gym class. At } \\
\text { recess there aren't } \\
\text { many sports." }\end{array}$ & \\
\hline
\end{tabular}

In order to infer if the children and parents perceived this kind of approach as effective and promising for the future implementation, interviews involving open-ended questions were carried out. The information conveyed by the children is presented in Table 2, whereas the information gathered from the parents is presented in Table 3.

Table 3: Qualitative data gathered during the interview with the parents.

\begin{tabular}{|c|c|c|}
\hline Question & Male's Father & Female's Father \\
\hline $\begin{array}{c}\text { Does your child } \\
\text { generally enjoy/play } \\
\text { video games, active } \\
\text { or otherwise? }\end{array}$ & $\begin{array}{l}\text { "Both, on his DS a lot } \\
\text { of the time but loves } \\
\text { to go hiking." }\end{array}$ & $\begin{array}{l}\text { "No she doesn't at all } \\
\text { but she will watch } \\
\text { her sister or mom. } \\
\text { A bit of increase } \\
\text { in participation in } \\
\text { school after this } \\
\text { study." }\end{array}$ \\
\hline $\begin{array}{l}\text { Do you think that this } \\
\text { intervention may be } \\
\text { effective? If not, why } \\
\text { not? }\end{array}$ & $\begin{array}{l}\text { "I think it will be, } \\
\text { he tends to peak } \\
\text { with these things } \\
\text { but hopefully he will } \\
\text { maintain it." }\end{array}$ & $\begin{array}{l}\text { "We would have to } \\
\text { compare to real life } \\
\text { sports to see." }\end{array}$ \\
\hline $\begin{array}{l}\text { Would you be } \\
\text { able to see your } \\
\text { child perusing this } \\
\text { intervention for an } \\
\text { extended period of } \\
\text { time? }\end{array}$ & $\begin{array}{l}\text { "Oh for sure, he loves } \\
\text { doing these things." }\end{array}$ & $\begin{array}{l}\text { "She prefers the } \\
\text { interaction with } \\
\text { people rather than on } \\
\text { her own with a video } \\
\text { game. Definitely } \\
\text { during the winter } \\
\text { months it would be } \\
\text { good." }\end{array}$ \\
\hline $\begin{array}{l}\text { Would you do this } \\
\text { study at home with } \\
\text { your child? }\end{array}$ & $\begin{array}{l}\text { "Yes, I try to do as } \\
\text { many active things } \\
\text { with him as he will } \\
\text { let me." }\end{array}$ & $\begin{array}{l}\text { "Yes, it's one of the } \\
\text { things we talked } \\
\text { about with her." }\end{array}$ \\
\hline $\begin{array}{l}\text { Do you think that } \\
\text { your child gained } \\
\text { more self-confidence } \\
\text { in movement skills? }\end{array}$ & "Yes." & $\begin{array}{l}\text { "Over the last month, } \\
\text { it has worked out to } \\
\text { be a benefit for her. } \\
\text { Having someone else } \\
\text { push her to do things } \\
\text { other than Mom and } \\
\text { Dad." }\end{array}$ \\
\hline
\end{tabular}

\begin{tabular}{|c|c|c|}
\hline $\begin{array}{c}\text { Do you think your } \\
\text { child improved in } \\
\text { his/her physical } \\
\text { abilities through } \\
\text { these interventions? }\end{array}$ & "Yes." & $\begin{array}{c}\text { "I don't really know } \\
\text { because I didn't } \\
\text { watch during the } \\
\text { study." }\end{array}$ \\
\hline $\begin{array}{c}\text { What would you do, } \\
\text { if anything, to make } \\
\text { this program more } \\
\text { effective? }\end{array}$ & "I honestly don't \\
know." & $\begin{array}{c}\text { "Repetition and } \\
\text { timing. Later in the } \\
\text { evening causes her } \\
\text { attention to wander. } \\
\text { Having a consistent } \\
\text { time would be nice." }\end{array}$ \\
\hline $\begin{array}{c}\text { Do you think that } \\
\text { your child enjoyed } \\
\text { the program } \\
\text { and would you } \\
\text { recommend it to } \\
\text { other parents looking } \\
\text { for physical activity } \\
\text { programs for their } \\
\text { children? If not, why } \\
\text { not? }\end{array}$ & "Yes, he looked & $\begin{array}{c}\text { it. I don't think she } \\
\text { enjoyed it as much } \\
\text { as physical games } \\
\text { because she doesn't } \\
\text { really like video } \\
\text { games." }\end{array}$ \\
\hline $\begin{array}{c}\text { Can you visibly see } \\
\text { the differences in } \\
\text { your child's physical } \\
\text { abilities since the } \\
\text { start of the program? }\end{array}$ & week." & \\
\hline
\end{tabular}

\section{Discussion}

\section{Outcome data}

The objective of the current pilot study was two-fold. The first was to examine the effects of playing active virtual motion (Xbox Kinect) on balance control, agility and performance of core movement skills in two children diagnosed with Developmental Coordination Disorder. The emerging results were mixed.

The analysis of MABC-2 scores showed substantial improvements in ball skills and balance control for both children. In terms of the first domain, when the normative data was reviewed it was evident that both children improved from being below 10 percentile to 63rd and 25th respectively, as inferred from MABC-2 norms. Even when considering the measurement error associated with individual sub-sections, such change in scores has to be considered as "real". These positive changes were seen gradually over the initial part of the study, and then at the retention tests confirming that these improvements were relatively permanent. Intuitively, when considering the nature of the games being played (e.g. tennis), generating such actions effectively does force the player to implement good hand-eye coordination, interceptive (timing) skills and suitable intra-limb coordination between the different joints of the arm involved. All these underlying abilities are also critical in manual skills regardless if they are occurring under external time demands (e.g. catching) or are self-paced (e.g. aiming and throwing). Thus, the implementation of the tasks included in MABC-2 allows to make inferences in regards to the generalizability/transferability of the skills practiced via virtual games to real-life tasks. These results do not confirm previous findings $[13,14,16]$, which 
showed no substantial changes in this domain as inferred from MABC-2. However, it should be noted that these investigations implemented a Wii Fit program, whereas this study involved Xbox system. It is plausible that the degree to which the virtual games are effective may be constrained by the type of the games played, as well as the technology used. The games available in the market vastly differ in terms of type of movements they allow and the nature of the interaction with the screen and surrounding environment [20].

The inferences emerging from the ball skills were in line with those involving balance control tasks. Both children were positively affected by the virtual games played, and considering their nature it can be speculated that soccer and wake racing activities contributed to these improvements. Although conceptually balance control is a specific skill rather than a general motor ability [21], the changes in MABC-2scores were not surprising since the tasks involved in the test (e.g. standing on one foot) are comparable to those involved in the games (e.g. standing on one leg while attempting to kick the virtual ball). In relation to previous research involving balance control tasks/ measures once again the inferences were mixed. Straker et al. [13] showed no changes in balance control as inferred from MABC and COP measures. However, the expected effects were evident in the studies by Jelsma and colleagues involving static [16] and dynamic balance tasks [22], as well as in other studies showing improved balance control as measured via MABC-2 and BOT-2 tests [14]. Collectively, it appears that among all the motor domains that are possibly affected by the virtual games, regardless of the type of the game or the system implemented the positive effects on balance control are robust across majority of the studies.

The analysis of the BOT-2 scores, in regards to strength and running speed/agility, showed a different scenario. The review of the scores (Figure 4) showed that both children varied greatly across the testing sessions, even if the male participant was performing slightly better. This may be due to his age and likely gender. However, as evident from the retention tests, the scores were comparable or even lower than those obtained at the pretest, indicating that the changes emerging during the study were not due to "true" learning. These results are in line with previous research examining these domain via subsections of BOT-2 [15], as well as other measures of speed/agility such as $2 \mathrm{~min}$ walk test [23] and $20 \mathrm{~m}$ shuttle run test, as well as strength [14]. Although at face value it is somewhat surprising that certain domains are affected by the active virtual games, whereas others are not, conceptually and intuitively these results are logical. Among the different physical proficiency domains, as outlined by Fleishman [24], abilities such as speed of movement, gross body coordination, stamina and strength represent different aspects of motor functioning. Thus if the games implemented in the intervention are geared more towards interceptive/timing or perceptuo-motor tasks, the domains such as strength or running speed should not be affected. Stated differently, the nature of the games implemented is an important constraint which needs to be considered given the needs of the persons involved in the intervention.

\section{Qualitative data}

In order to infer if the children and parents perceived this kind of approach as effective and promising for the future implementation, interviews involving open-ended questions were carried out. The information conveyed by the children showed an overall positive outlook towards the games, from the stand point of enjoyment and future participation. However, they were also sceptical in regards to how, or if, these tasks were similar to those performed in real-life. In terms of how the skills practised here would translate into enhancement of their motor performance in every-day physical activities, the responses varied. The interview with parents revealed that both children had mixed interest in the video-games which may impact how much they have gained from the sessions. However, they confirmed that playing such games was enjoyable for the children and that they may have a positive impact on their motor performance. However, they also stressed that importance of transferability to real-life situations, and the fact that playing games alone takes away from interaction with other kids. Also, although both indicated that they would try this approach at home, by the end of the study only parent acknowledged a potential change in the child's physical capabilities.

\section{Conclusion}

The results of this pilot project although warrant caution due to small sample size contributed to the existing knowledge base. It was shown that Exbox games, just like the Wii system implemented in previous studies, resulted in positive changes in motor proficiency. However, the results from this and previous investagions also showed that the nature of the resulting perceptuo-motor effects is specific to certain domains and not others (e.g. stamina; strength). Thus the nature of the tasks implemented in the games, along with the individual constraints of the participants, represent an important factor that the clinicians or parents should consider when implementing these games. From the stand point of enjoyment, motivation and feasibility for future implementation, both children and parents had very positive outlook. However, the questions regarding the transferability of the skills acquired via gaming to real life tasks is still unclear. Also, the fact that these games are often played in isolation does not enhance or affected the social dynamics and sense of belonging which can be achieved during free play. Although virtual gaming presented in group setting would take away from the experimental control of the study, from the practical perspective it may enhance child's enjoyment of the games, stimulate effort and the necessity for establishing and maintaining social interactions with peers of same/similar age and skill level. In summary, the evidence seems to support 
the use of active video games as an enjoyable medium for selfdirected physical activity of light to moderate intensity. However, as emphasized earlier, playing active video games should not be considered as a replacement of vigorous sport activities, but rather as a possibility to convert time spent on passive/ sedentary gaming to more active routines.

\section{References}

1. American Academy of Pediatrics (2001) Children, adolescents, and

2. Janssen I, LeBlanc AG (2010) Systematic review of the health benefits of physical activity and fitness in school-aged children and youth. Int J Behav Nutr Phys Act 7(40): 17-40.

3. Goble DJ, Cone BL, Flink BW (2014) Using the Wii Fit as a tool for balance assessment and neuro rehabilitation: the first half decade of "Wii-search". J Neuroeng Rehabil 11(12): 1-9.

4. Shea JB, Morgan RL (1979) Contextual interference effects on acquisition, retention and transfer of a motor skill. Journal of Experimental Psychology 5: 179-187.

5. Schmidt RA (1975) A schema theory of descerete motor skill learning. Jounral of Experimental Psychology 79: 43-47.

6. Straker LM, Campbell AC, Jensen LM, Metcalf DR, Smith AJ, et al. (2011) Rationale, design and methods for a randomised and controlled trial of the impact of virtual reality games on motor competence, physical activity, and mental health in children with developmental coordination disorder. BMC Public Health 11: 654.

7. Wuang YP, Chiang CS, Su CY, Wang CC (2011) Effectiveness of virtual reality using Wii gaming technology in children with Down syndrome. Res Dev Disabil 32(1): 312-321.

8. Shaffer RJ, Jacokes LE, Cassily JF, Greenspan SI, Tuchman RF, et al. (2001) Effect of interactive metronome training on children with ADHD. Am J Occup Ther 55(2): 155-162.

9. American Psychiatric Association (2000) Diagnostic and Statistical Manual of Mental Disorder. American Psychiatric Association, Washington, USA.

10. Larkin D, Hoare D (1992) The movement approach: a window to understanding the clumsy child. In JJ Summers (Eds.), Approaches to the study of motor control and learning, Amsterdam, North Holland, pp. 413-439.

11. Kwan MY, Cairney J, Hay JA, Faught BE (2009) Understanding physical activity and motivations for children with developmental coordination disorder: an investigation using the theory of planned behaviour. Res Dev Disability 34(11): 3691-3698. television. Pediatrics 107(2): 57-59.

12. Gonsalves L, Campbell A, Jensen L, Straker L (2015) Children with developmental coordination disorder play active virtual reality games differently than children with typical development. Phys Ther 95(3): 360-368.

13. Straker L, Howie E, Smith A, Jensen L, Piek J, et al. (2015) A crossover randomised and controlled trial of the impact of active video games on motor coordination and perceptions of physical ability in children at risk of developmental coordination disorder. Hum Mov Sci 42: 146160.

14. Ferguson GD, Jelsma D, Jelsma J, Smits-Engelsman BC (2013) The efficacy of two task-orientated interventions for children with Developmental Coordination Disorder: Neuromotor Task Training and Nintendo Wii Fit Training. Res Dev Disabil 34(9): 2449-2461.

15. Hammond J, Jones V, Hill EL, Green D, Male I (2013) An investigation of the impact of regular use of the Wii Fit to improve motor and psychosocial outcomes in children with movement difficulties: a pilot study. Child Care Health Dev 40(2): 165-175.

16. Jelsma D, Geuze RH, Mombarg R, Smits-Engelsman BC (2014) The impact of wii fit intervention on dynamic balance control in children with probable developmental coordination disorder and balance problems. Hum Mov Sci 33: 404-418.

17. Ashkenazi T, Weiss PL, Orian D, Laufer Y (2013) Low-cost virtual reality intervention program for children with developmental coordination disorder: a pilot feasibility study. Pediatr Phys Ther 25(4): 467-73.

18. Barnett A, Henderson SE, Sugden DA (2007) Movement Assessment Battery for Children-Second Edition (Movement ABC-2). Psychological Corporation, London.

19. Bruininks RH, Bruininks BD (2005) Bruininks-Oseretsky test of motor proficiency. $\left(2^{\text {nd }}\right.$ edn), Pearson, Minneapolis, USA.

20. Howie EK, Campbell AC, Abbott RA, Straker LM (2017) Understanding why an active video game intervention did not improve motor skill and physical activity in children with developmental coordination disorder: A quantity or quality issue? Res Dev Disabil 60: 1-12.

21. Drowatzky JN, Zuccato FC (1967) Interrelationships between selected measures of static and dynamic balance. Res Q 38(3): 509-510.

22. Jelsma LD, Smits-Engelsman BC, Krijnen WP, Geuze RH (2016) Changes in dynamic balance control over time in children with and without Developmental Coordination Disorder. Hum Mov Sci 49: 148-159.

23. Salem Y, Gropack SJ, Coffin D, Godwin EM (2012) Effectiveness of a low-cost virtual reality system for children with developmental delay: a preliminary randomised single-blind controlled trial. Physiotherapy 98(3):189-195.

24. Fleishman EA (1967) Development of behavior taxonomy for describing human tasks: A correlational-experimental approach. Journal of Applied Psychology 51(1): 1-10.

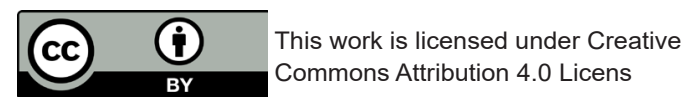

\section{Your next submission with Juniper Publishers will reach you the below assets}

- Quality Editorial service

- Swift Peer Review

- Reprints availability

- E-prints Service

- Manuscript Podcast for convenient understanding

- Global attainment for your research

- Manuscript accessibility in different formats

( Pdf, E-pub, Full Text, Audio)

- Unceasing customer service

Track the below URL for one-step submission https://juniperpublishers.com/online-submission.php 